\title{
Hobbes y la tragedia del lenguaje
}

\author{
Eduardo Rinesi \\ UNGS - Universidad Nacional de General Sarmiento \\ rinesi@hotmail.com
}

resumen Lo que el título de este artículo designa como "la tragedia del lenguaje" constituye una de las dimensiones del "trasfondo trágico" sobre el que se recortan las líneas mayores de la gran teoría política moderna. Me gustaría mostrar que hay una dimensión propiamente trágica en el pensamiento de Hobbes y que una parte importante de la tragedia con la que lidia el autor del Leviatán es la que se refiere a las palabras y sus significados, e ilustrar este punto a partir de una comparación entre el tratamiento que da Hobbes al problema del lenguaje y el que puede encontrarse en una pieza literaria mayor del teatro isabelino: Hamlet, de Shakespeare, donde esa "tragedia del lenguaje" se expresa a través de numerosos y célebres juegos de palabras. Eso nos permitirá, adicionalmente, ensayar una reflexión sobre la relación entre la tragedia y la comedia, y observar el modo en que el pensamiento hobbesiano limita y dialoga con ambas.

palabras clave Lenguaje; tragedia; comedia; Maquiavelo; Shakespeare; Hobbes

Contra la tendencia algo escolar a preguntarse cuándo, con qué obra, con qué autor puede declararse inaugurado el ciclo del pensamiento político moderno, Quentin Skinner ha utilizado, en el título de su libro más famoso, Foundations of modern political thought, un conveniente plural que remite, en una dirección, a los años del renacimiento italiano, especialmente florentino (y sobre todo, claro, a la obra del viejo Maquiavelo), y en otra dirección a los años de las grandes luchas civiles y religiosas de la Europa reformada (y sobre todo, claro, a la obra de Thomas Hobbes). El capítulo moderno de la historia del pensamiento político occidental no 
tendría entonces un único portal, sino que sería posible entrar a él por dos vías diferentes -la teoría de la acción política del autor de El Príncipe y de los Discorsi y la teoría de las instituciones políticas del autor del De Cive y del Leviatán-, y en cierto sentido el desarrollo posterior de ese pensamiento político moderno no dejaría de tener la forma de un prolongado diálogo entre las entonaciones de esos dos impulsos iniciales. Lo único que querría yo agregar a esta idea es que si, en efecto, la historia del pensamiento político moderno puede pensarse como la larga conversación (por supuesto que llena de tensiones) entre lo que podemos llamar, usando la expresión de John Pocock, su "momento maquiaveliano" y lo que podemos llamar también, abusando apenas de ella, su "momento hobbesiano", entonces esa historia del pensamiento político moderno es la historia de la conversación entre dos teorías caracterizadas por lo una entonación decididamente trágica.

Una entonación, en otras palabras, animada por la doble convicción de que existen en el mundo conflictos que son irreductibles e ineliminables y de que, por lo mismo, ningún orden puede dejar de ser insanablemente frágil y precario. Eso es, si debiéramos decirlo con la mayor concisión, lo que nos enseña siempre la tragedia. Porque hay tragedia, en efecto, cuando hay en el mundo (casi no importa aquí si en el mundo olímpico de los dioses, como en la tragedia antigua, o en el mundo anímico de un sujeto atormentado por la duda moral, como en la tragedia moderna) un conflicto o una serie de conflictos irreductibles, y lo que la tragedia tiene para enseñarle al pensamiento sobre la política es exactamente que es con ese tipo de conflictos con los que ese pensamiento no tiene más remedio que lidiar. Pues bien: la idea que estoy sugiriendo aquí es que los pensamientos de los dos autores que sirven de sendas vías de entrada al pensamiento político de la modernidad (ya lo dije: Maquiavelo y Hobbes) comparten este mismo carácter "trágico", en la medida en que son pensamientos que aceptan "reflexionar sobre el mundo reconociendo en él ámbitos de conflicto irreductible" (SIPERMAN, 2000, p. 36). Adicionalmente, me gustaría proponer que, justamente por eso, es posible y productivo poner en diálogo estos pensamientos con el espíritu de ese gran momento en la historia de la literatura y la cultura occidental que es el momento signado por el desarrollo de la gran tragedia isabelina en la Inglaterra de fines del siglo XVI y 
comienzos del XVII. Me gustaría sugerir, en este sentido, que las grandes tragedias de Shakespeare (entre las que voy a usar aquí como ejemplo sólo una, la más famosa, la más enigmática y seguramente la mejor: Hamlet) pueden ser leídas como sitios donde escuchar tanto los ecos de la gran revolución conceptual operada en la obra de Maquiavelo cuanto las anticipaciones de algunas de las ideas fundamentales que más tarde desarrollaría Hobbes.

En ese sentido, no sería difícil encontrar en Hamlet, en efecto, algunas resonancias bien notorias de lo que podríamos quizás identificar como las dos grandes tragedias que atraviesan (y que tematiza) la obra de Maquiavelo. Por un lado, lo que podemos llamar "la tragedia de los valores". Que no consiste tanto en el hecho de que en Maquiavelo la política -como se ha pretendido muchas veces- se separe de la moral (esto es falso, pero además, si fuera verdadero, no configuraría ninguna situación trágica), ni tampoco en la verificación -en cualquier caso más sutil- de que habría en Maquiavelo, contra la hipócrita "política de manos limpias" de sus adversarios teóricos, el elogio de una más francamente humanista "ética de la responsabilidad" política, sino en la comprobación de que lo que Maquiavelo hace es mostrarnos, mucho más perturbadoramente, que no existe en el mundo un único sistema de valores legítimos y justos. Con lo que la decisión de cualquier actor político no es nunca, como lo había querido la tradición cristiana, la de saber cómo hacer triunfar la virtud sobre el pecado y el bien sobre el mal, sino la de saber a qué dioses, a cuál de los distintos sistemas de valores que existen (y cada uno de los cuales -ésa es la tragedia- tiene todo para decir a su favor) ha de serse fiel. ¿Y no es exactamente esa dificil decisión la que el buen príncipe Hamlet no hace más que postergar a lo largo de los cinco actos del drama de Shakespeare, tensionado como está entre la obediencia a un sistema de valores en nombre del cual el espectro de su padre le ha ordenado vengar su asesinato y la sujeción a otro sistema de valores que le susurra que si cumpliera con esa orden no dejaría de convertirse él mismo en esa cosa despreciable (un rey asesino que ha matado a su antecesor) que quiere eliminar? ¿Y no es exactamente ése el sentido que hay que darle a esa interesante frase que al comienzo de la última escena Hamlet le dice a su amigo Horacio: "En mi corazón había una suerte de lucha" (HAMLET, 5.2.4), verdadero resumen de toda la pieza? 
Por otro lado, en Maquiavelo encontramos lo que podríamos llamar una "tragedia de la acción". Que consiste en que si, incluso en ausencia de todo criterio trascendente y exterior para juzgar los méritos relativos de dos sistemas de valores, el actor político (digamos, el príncipe) terminara por decidirse por uno de ellos y actuara con la mayor energía y decisión para alcanzar los fines que ese sistema de valores le señala como ambicionables, sus posibilidades de alcanzar efectivamente esos fines nunca dependerían sólo de la decisión que empeñara en alcanzarlos, ni de su capacidad ni de su astucia, porque ese conjunto de aptitudes -a las que Maquiavelo da el nombre clásico de virtù- deben enfrentar siempre a las fuerzas del acaso, de lo contingente y de lo imprevisible, que pueden dar por tierra con el plan mejor elaborado. A esas fuerzas Maquiavelo (siguiendo también una larga tradición) les da el nombre de Fortuna, y es sabido que la discusión sobre la naturaleza de ese combate entre la Fortuna y la virtù constituye un capítulo fundamental de su pensamiento teórico sobre la política. Lo que aquí estoy agregando es que -primero- ése es otro motivo para calificar ese pensamiento teórico sobre la política como un pensamiento trágico, y que -segundo- es de nuevo fácil encontrar en Hamlet una preciosa ilustración literaria de este tópico. ¿ $\mathrm{O}$ no es exactamente de esto de lo que habla el monólogo más famoso de toda la literatura shakespeareana al oponer la decisión del sujeto de "tomar las armas contra un mar de adversidades / y enfrentándolas ponerles fin" (3, 1, 59-60) -es decir, de apelar a su virtù para dar combate contra los males del mundo- a las agresiones de "los dardos y flechazos de la insultante fortuna", siempre amenazante y siempre imprevisible?

De manera que la "puerta Maquiavelo" a la modernidad teóricopolítica es una puerta decididamente "trágica". Pero querría sugerir que no lo es menos la otra de las puertas a ese mismo universo conceptual: la "puerta Hobbes", sostenida sobre dos categorías fundamentales -la del "estado de naturaleza" y la del "contrato"- cuyo tratamiento en la obra de Hobbes participa del universo del arte trágico tal vez más todavía de lo que el filósofo inglés habría estado dispuesto a admitirlo. Es fácil verlo en relación con la idea de "estado de naturaleza", de ese natural state of mankind, de esa "condición natural" que lleva a los hombres a pelar unos contra otros, como dice Hobbes en el capítulo 
XIII del Leviatán, "por competencia, por prudencia y por honor". Esta famosísima frase de Hobbes es por supuesto muy interesante. Por un lado, no es difícil oír en ella los ecos de otra frase, que el propio Hobbes había traducido del griego cuando joven, que es la frase en la que Tucídides apuntaba, como motivos de la guerra del Peloponeso, el miedo, el afán de gloria y el interés. Por otro lado, su estructura tripartita ha permitido a los distintos lectores de Hobbes acentuar uno u otro de esos motivos como causa fundamental de la guerra de todos contra todos, y así, por ejemplo, destacar -como hace Crawford Macphersonel motivo "burgués" de la competencia, o subrayar -como hace Leo Strauss- el tópico "aristocrático" del honor, posibili-dades que son tan interesantes por lo que permiten iluminar como simplificadoras cuando se las absolutiza, porque lo más interesante del señalamiento hobbesiano de que no existe una sola causa de la guerra, de que la guerra responde, como dos siglos y medio más tarde escribiría Sigmund Freud, a "toda una serie de motivos" (FREUD, 1982, p. 193) -de que la guerra, en otras palabras, no es el resultado contingente de una causa más o menos circunscripta y combatible, sino una necesidad inscripta en la propia naturaleza de los hombres y de sus relaciones- es el doble corolario de que nunca podemos estar del todo libres de ella, de que la guerra siempre aguarda, por debajo o por detrás de cualquier orden, como una posibilidad cierta y siempre amenazante.

La guerra, entonces, como una suerte de núcleo real irreductible de todas las relaciones entre los hombres, que se pelean entre sí por todo tipo de objetos de deseo, porque los hombres siempre desean los objetos deseados por el otro, porque los hombres siempre desean ser objetos del deseo del otro. Todo esto es hoy, por supuesto, tres siglos y medio después de Hobbes, de sobra conocido gracias al psicoanálisis, pero repárese en que no es otro que éste - de nuevo- el núcleo problemático de Hamlet, que parece ilustrar admirablemente, cuarenta años antes de que Hobbes la formulara, la categoría hobbesiana de "estado de naturaleza". Porque, en efecto, ¿qué es lo que tenemos en la Dinamarca desquiciada de nuestro buen príncipe Hamlet sino una guerra de todos contra todos, una serie de asesinatos guiados por la codicia, el amor, el deseo de venganza, la sed de gloria y la prudencia ante los comportamientos temibles de los otros? Algunas de estas causas pesan más en algunos de 
los crímenes; otras pesan más en otros, pero no está de más recordar que cuando el mismísimo rey Claudio evoca para sí mismo las razones por las que mató a su hermano, no menciona una sino - de nuevo- tres: "mi corona"-dice-, "mis propias ambiciones y mi reina" (3.3.55), sin que sea posible decir cuál de ellas fue la decisiva. ¿Cuál es la causa de las luchas y de la guerra entre los personajes de la mayor pieza de Shakespeare? Ningún objeto en particular, sino el hecho de que los hombres siempre desean de más. ¿Por qué luchan los hombres, en Shakespeare como en Hobbes? Por naturaleza. Es decir: por su simple, problemática y humana, demasiado humana, naturaleza de seres deseantes.

En cuanto a la otra categoría hobbesiana que hemos apuntado, la del contrato, es claro que la misma se levanta sobre un fondo trágico que la vuelve siempre, necesariamente, mucho menos tranquilizadora que lo que a primera vista podría parecer. El contrato es lo que les permite a los hombres hobbesianos salir del estado de naturaleza e ingresar a la sociedad civil reglada, y en ese sentido no hay duda de que también de lo que esta categoría viene a propiciar puede leerse una especie de versión anticipada en muchas de las piezas de Shakespeare. Característicamente, los finales de las tragedias shakespeareanas (el de Romeo y Julie-ta, con el intendente de Verona invitando a los padres de los dos jóvenes muertos a dejarse de peleas en el futuro, a darse la mano y a vivir en paz, o el de la propia Hamlet, con el futuro rey de Dinamarca, Fortimbrás, ordenando que se retiren los cuerpos de la escena -porque "esto semeja un campo de batalla" (5.2.381), dicey pidiendo al intelectual Horacio, que sobrevivió a los hechos para poder actuar como testigo de ellos y narrarlos, que lo ayude con ese relato a garantizar la paz futura de ese reino) parecen anticipar, en efecto, el núcleo central de la idea hobbesiana de contrato. Pero es claro que, tal como la plantea Hobbes, esa idea de contrato tiene muchos problemas para sostenerse como la efectiva garantía del pasaje de la guerra de todos contra todos a la sociedad civil reglada, toda vez que la posibilidad misma de su celebración -cito aquí a Luiz Eduardo Soares- "exigiría condiciones de orden y estabilidad de expectativas sólo realizables bajo la vigencia del estado de sociedad" (SOARES, 1995, p. 244), estado que es por su parte, y paradójicamente, hijo de ese mismo pacto. El círculo vicioso parece ilevantable: si el objetivo de 
Hobbes hubiera sido el de explicar, a través de la hipótesis del contrato, el pasaje del estado de naturaleza a la sociedad civil, su resultado sería por lo menos muy problemático.

Pero es que el objetivo de Hobbes nunca fue ése. En efecto, como ha sido ya reiteradamente señalado (por ejemplo, y de especial importancia para mi propia comprensión de este problema, por Renato Janine Ribeiro), la preocupación de Hobbes no es explicar el pasaje del hombre natural al hombre civil (pasaje que, entre otras cosas, y como todo el mundo sabe, no ha ocurrido jamás), sino inducir a sus lectores a reconocer al Estado, al Leviatán, como creación suya, a reconocerse como autores de ese Levia-tán, y, consecuentemente, como ciudadanos obligados a obedecerle. La teoría de Hobbes no cuenta una historia: demuestra, argumentativamente, racionalmente, una obligación de obedecer. El problema es que no todo el mundo está dispuesto a aceptar el argumento racional que lo obliga a algo tan gravoso, y éste es exactamente el lugar, el incómodo y al mismo tiempo decisivo lugar, en la teoría de Hobbes, del famoso fool, del necio. Que, si estoy en lo cierto, es menos un tipo de ciudadano que un tipo de lector, de lector del propio Hobbes. El fool pone en aprietos toda la teoría de Hobbes porque es el que no quiere entenderla, y aquél por culpa del cual el Estado en el que piensa Hobbes no puede descansar apenas en la legitimidad que le otorga esa teoría, sino que tiene que ser, también, un aparato de coacción. La coacción es la ultima ratio del Estado, pero que tenga que serlo es lo que revela, por el revés y al mismo tiempo, la precariedad de sus títulos y su fragilidad esencial. Un estado cuya estabili-dad depende del uso de la fuerza es un estado esencialmente inestable. De nuevo, la tragedia de la disolución del orden asedia y amenaza a la política -y otra vez nos tienta la posibilidad de presentar a Hamlet como un buen ejemplo de esto- desde el interior mismo de ese orden.

Y por esta vía nos terminamos de acercar al tema que les quería plantear. Permítanme presentarlo recordando un texto a esta altura clásico de Sheldon Wolin, Politics and vision, en el que el profesor norteamericano subraya esa esencial inestabilidad del mundo hobbesiano destacando la importancia que para el autor del Leviatán tiene la inestabilidad del significado de las palabras, inestabilidad que constituye por cierto una manifestación fundamental de la crisis de la cosmovisión medieval que las 
obras de Maquiavelo, de Hobbes (y también de Shakespeare) expresan y sintomatizan. Porque, en efecto, en el mismo movimiento por el cual Dios desaparece del centro de las representaciones simbólicas de los hombres europeos del Renacimiento como garantía última de su destino y como referencia última de sus valores morales, lo que debemos observar ahora es que desaparece también como garantía última del significado de las palabras. O, mejor: de la adecuada, de la "natural" relación permítanme una cita ruidosa- entre las palabras y las cosas que ellas designan. Porque si antes del Renacimiento esa relación, ese lazo, estaba garantizado por lo que Michel Foucault designó, en su enorme libro de 1964, como "la profunda pertenencia del lenguaje y el mundo", esa profunda y recíproca pertenencia, esa inmanencia de las palabras y las cosas, de las palabras en las cosas, esa antigua "existencia propia del lenguaje, su vieja solidez de cosa inscripta en el mundo" desaparecerá con la "inmensa reorganización de la cultura" que introducirá, en el hiato abierto de ese modo entre los signos y el mundo, el aparato de la representación, y con él, el engaño, la mentira y la posibilidad de la manipulación política del otro (FOUCAULT, 1966, p. 58). En efecto, disuelto el lazo natural (o divino) que las ligaba a sus referentes, las palabras comienzan a vagar libres por el mundo, con la posibilidad de adquirir más de un significado y de convertirse, ellas mismas, en el objeto o incluso en el campo de una batalla por el sentido.

Esta "liberación de las palabras", por así decir, constituye una fundamental condición de posibilidad para el surgimiento de una noción moderna de la política. Porque la política -la política en un sentido moderno, propio y fuerte- presupone la existencia de significados dife-rentes para las palabras. No habría política, en efecto, si todas las personas entendieran lo mismo por palabras tales como "libertad", "justicia" o "Dios". No habría política si todos entendieran en el mismo sentido una frase como, por ejemplo, "todos los hombres son iguales", frase que en efecto la mayor parte de los hombres suscribiría, sólo que seguramente entendiendo cosas muy distintas tanto por "hombre" como por "igualdad". La política comienza allí donde entran en escena estas diferencias. Por eso es condición de posibilidad de la política la existencia o la posibilidad de existencia de significados múltiples para las palabras. Y por eso, también, no es posible hablar 
propiamente (o por lo menos: modernamente) de "política" antes de la explosión de esa "episteme" pre-moderna que "ataba" el significado de cada palabra a una "cosa" determinada con un lazo que el hombre era demasiado débil para deshacer. Es sólo cuando ese lazo se disuelve y el mundo queda habitado por una cantidad de "palabras" vagando libremente, "fuera de quicio" (out of joint, para usar la célebre expresión de Hamlet), sin relaciones fijas que las unan a las "cosas", que la política puede aparecer, porque puede aparecer el conflicto y la lucha por el significado de esas palabras, de esos "signos".

Es sólo entonces, también, que la filosofía política (notoriamente a partir de Hobbes y del conjunto de los autores que solemos rotular como pertenecientes al gran racionalismo filosófico) puede asumir la tarea de conjurar ese estar fuera de quicio de los signos, esa proliferación de palabras errantes, fijando su sentido, volviendo a atar sus significados, no ya en una Escritura Divina, sino en una escritura secular, laica y racional: la escritura geometrizante de la Ciencia. Otro modo, entonces, de caracterizar el período que nos interesa aquí -el período que se abre en los días de Maquiavelo y se va cerrando en los de Hobbes- sería decir que es aquél que se inaugura con el agotamiento de una cosmovisión asociada con la idea de un poder divino que ataba las cosas del mundo con los nombres que les había puesto su creador y se clausura con el surgimiento del gran proyecto racionalista de reinstaurar esa ligazón a través de ese otro tipo de "Palabra", que es ahora la palabra racional y laica de la Ciencia. Y otro modo de justificar mi interés por pensar la mayor tragedia inglesa de este período como expresión de todas estas discusiones, e incluso como telón de fondo de las reflexiones hobbesianas acerca del lenguaje, sería decir que Hamlet tematiza o alegoriza lo que ocurre cuando las palabras, por así decir, " ya" se emanciparon de su atadura natural o divina con las cosas, pero "todavía" no lograron amarrar su significado al nuevo Orden simbólico, obligatorio y universal, que vendría a reemplazar al que se había agotado. Entre ese "ya" y ese "todavía”, las palabras parecen boyar en un mar de incertidumbres, sin vínculos estables con el fondo firme de los significados aceptados y compartidos, y convertidas en objeto de todo tipo de disputas y querellas.

Así, resumiendo, lo que hemos propuesto llamar "la tragedia del lenguaje" consiste en que las palabras pueden querer decir más de una 
cosa al mismo tiempo, y en que (erosionada ya la garantía trascendente de Dios, ausente todavía la exterioridad trascendente de la Ciencia y del Estado que Hobbes pugna por instalar) no hay ningún criterio objetivo para saber cuál es su significado "verdadero".Y lo que me gustaría ahora señalar es que en este punto, como en tantos otros, la literatura se adelanta a la historia: que en este punto Hamlet, una vez más, se adelante a la guerra civil inglesa y al pensamiento teórico de Hobbes, trazando, con caracteres sorprendentemente premonitorios, una preciosa estilización del fantasma de esa situación de desorden y subversión contra la cual el filósofo inglés, medio siglo más tarde, se debatiría. En Hamlet, en efecto, la ambigüedad del sentido de las palabras es constitutiva de esa situación en la que el mundo, como ya dijimos, está "fuera de quicio", y en la cual, por eso, la tragedia encuentra su lugar. Por eso son tan importantes, en Hamlet, los juegos de palabras. Que por cierto no son un adorno, un ornamento, una demostración del arte cómico de Shakespeare al servicio de la decoración del "argumento" de su pieza, sino que constituyen una parte fundamental de ese argumento. En efecto, si los juegos de palabras son tan abundantes, están tan masivamente presentes todo a lo largo de Hamlet, es porque el tema de Hamlet es exactamente el de esa ambivalencia fundamental de las palabras que los hace posible y que ellos expresan. Así, por ejemplo, cuando Hamlet se promete recordar a su padre "Whiles memory holds a seat / In this distracted word" (1.5.96-7) (mientras la memoria tenga un sitio / en este globo trastornado), "globe", globo, puede aludir y de hecho alude tanto a la cabeza de Hamlet cuanto al mundo, a la esfera terrestre: el interés de la frase de Shakespeare radica en invitarnos a leerla al mismo tiempo en ambos sentidos.Y que ambos sentidos están simultánemante aludidos y mutuamente implicados es algo que se vuelve todavía más evidente si se repara en el modo permanente en el que, en Hamlet (y en el pensamiento renacentisa en general) individuo y cosmos actúan como metáfora uno de otro. Vale la pena recordar, además, que el teatro de la compañía de Shakespeare se llamaba The Globe, el globo, lo que viene a agregar una tercera alusión a la línea que comentamos, que es dificil imaginar que no haya estado en la mente de Shakespeare al escibirla, ni en la de sus espectadores al oírla. La idea, típicamente renacentista y shakespeareana, del mundo como teatro, se ve por lo demás reforzada, en esta frase que cita- 
mos (mientras la memoria tenga un sitio, "whiles memory holds a seat"), por la doble valencia de la palabra "seat", que es "sitio", por supuesto, pero también "asiento", "silla", "localidad"... en un teatro.

A veces Shakespeare juega con la sonoridad de las palabras, como en la respuesta que da Hamlet a Polonio diciéndole que es un pescadero (fishmonger) pero insinuando en realidad -a través de la cercanía sonora de las palabras- que es un fleshmonger, un rufián; otras veces lo hace con sus ambivalencias, como cuando la manda a la pobre Ofelia a una nunnery, que quiere decir "convento", pero también, en su uso popular, "prostíbulo". Cuando Claudio lo manda llamar para preguntarle dónde está Polonio, Hamlet le responde "At supper" (en una cena), y enseguida explica: "No en una cena donde él come, sino en una donde es comido. Una asamblea de gusanos lo está comiendo. El gusano es el único emperador de la alimentación" (4.3.19-21). Por supuesto, el chiste de la cena donde el pobre hombre está siendo comido es muy gracioso. No sé si Borges lo habrá tenido en cuenta cuando aludió, en su poema "Fundación mítica de Buenos Aires", al lugar "en que ayunó Juan Díaz y los indios comieron”, verso magnífico cuya gracia radica, obviamente, en que aquello que los indios comieron fue, precisamente, a Juan Díaz. Pero a ese chiste se agregan aquí varios más. Para empezar, "Diet", dieta, significa tanto "régimen alimenticio" como "asamblea", que es también el significado de "convocation". Ahora: la asamblea o banquete de la que habla Hamlet es una asamblea de gusanos, worms, a los cuales, por lo demás, Hamlet califica de "políticos", lo que si por un lado no deja de connotar a la figura del propio Polonio, político de profesión y participante privilegiado del banquete en cuestión (y de paso a Claudio, ciertamente), por otro lado remite -y aquí está el chiste- al nombre de la ciudad alemana de Worms, sede de una de las mayores Dietas de la época. Esas Dietas, igual que los parlamentos ingleses, eran eventualmente convocadas (y, naturalmente, presididas) por el emperador, en la ciudad que éste, en cada caso, escogiera. (En Worms, por cierto, había tenido lugar, convocada por Carlos V, la Dieta que en 1521 había condenado a Lutero). Designando al gusano "emperador" de la dieta (de la asamblea y de la comida), Hamlet utiliza el típico recurso cómico, grotesco, de replicar una escena "alta" (la del emperador y los políticos reunidos en solemne asamblea) con su inver- 
sión "baja", burlesca, carnavalesca: la de la "asamblea" de los verdaderos emperadores de todo el ciclo alimenticio y vital comiéndose a uno de esos políticos de la Corte.

Por cierto, los ejemplos de muy ingeniosos juegos de palabras en Hamlet podrían ocuparnos durante todo el resto de estas notas. Pero más que extenderme sobre esos ejemplos, me gustaría insistir en lo fundamental de lo que estoy tratando de plantear: que lo que he llamado "la tragedia del lenguaje" (el hecho, sin duda trágico y lleno de consecuencias desastrosas, de que las palabras no tienen significados únicos, universales y obligatorios, de que las personas no pueden entenderse por medio del lenguaje) se expresa, en Hamlet, en un tono y por medio de un recurso típicamente cómicos. Que la tragedia del lenguaje se expresa, a través de estos juegos y estas confusiones, en forma de comedia. Por cierto, esta unión, esta mezcla de elementos trágicos y cómicos (inimaginable en el antiguo teatro griego, en el que los dos géneros estaban nítidamente separados) constituye una característica muchas veces subrayada del drama isabelino y de la dramaturgia de Shakespeare en particular, y, de nuevo, podrían ofrecerse múltiples ejemplos de esto en cualquiera de las piezas shakespeareanas que quisiera tomarse como ejemplo: en Lear, en Romeo y Julieta, en cualquiera. En efecto, por medio de múltiples recursos -que van desde estos juegos de palabras hasta la inclusión de bufones y perso-najes cómicos y grotescos incluso en los momentos más elevados de sus obras-, Shakespeare siempre combina elementos trágicos y cómicos en el interior de sus composiciones, y muchas veces utiliza los recursos del humor para hablarnos de las grandes catástrofes que nos presenta. Lo que aquí querría decir, volviendo al eje central de nuestras preocupaciones de hoy, es que esa misma combinación está también presente en ese gran escritor que es Hobbes. Que Hobbes también combina un tono trágico y un tono cómico, o utiliza un tono cómico para mostrarnos las grandes tragedias de las que nos habla, y entre ellas la gran tragedia que aquí estoy presentando: la tragedia del lenguaje y de los signos.

Esta comicidad de Hobbes ha sido destacada muchas veces. Se han comentado ya en incontables ocasiones, en efecto, los múltiples recursos cómicos que utiliza Hobbes en sus explicaciones, y sobre todo en 
sus críticas (en particular, si uno recuerda los últimos dos libros del Leviatán, en sus críticas al catolicismo y al papado), como así también sus propios "juegos de palabras", que a veces - por cierto- no tienen nada que envidiarle a los del buen príncipe Hamlet. Recordemos aquí el famosísimo "Covenants without the sword are but words", que habla sobre las palabras y su volatilidad jugando con las palabras (de hecho, con la palabra "palabras": words) y con su volatilidad: haciendo en efecto revolotear de un lado a otro las letras que la componen para que se ordenen de otro modo y formen "sword", espada, que designa el único elemento que podría evitar que esas mismas acrobacias -de las letras, de las palabras, de los significados- se generalizaran y volvieran imposible la comunicación y la misma vida social. “¿Qué leéis, mi señor?”, le había preguntado el estúpido Polonio al buen príncipe Hamlet: "Words, words, words" (2.2.189) -había respondido el príncipe. ¿Qué serían los contratos sin la espada?- se pregunta Hobbes. "Words, words, words", responde. En uno y en otro lo que tenemos es la crítica a un mundo vuelto un montón de palabras que han perdido su sentido. En uno y en otro esa crítica se formula por medio de un juego de palabras: de un juego con el significado y la sonoridad de las palabras, y de la palabra "palabra" en particular.

En el importante libro que Quentin Skinner dedicó a Hobbes, el historiador inglés se pregunta por las razones de esta recuperación, en el Hobbes maduro, en el Hobbes posterior al racionalismo militante del De Cive, de este conjunto de recursos retóricos (incluido dentro de ellos el humor y los juegos de palabras) provenientes de la vieja tradición humanista en la que Hobbes se había formado de joven y con la que había roto, como es fama, a comienzos de los años 40. No parece necesario, y me alejaría de la última cuestión que querría plantearles hoy, detenernos en este problema. Bástenos decir que para un argumento que, como el de Hobbes, quería interpelar muy activamente a sus lectores, porque era un argumento que iba dirigido en primer lugar a producir un efecto en esos lectores (el efecto de una transformación subjetiva, el efecto del reconocimiento de la obligación personal de obedecer), era indispensable poder conquistar la conciencia de esos lectores, y que a Hobbes, según argumenta convincentemente Skinner, se le fue revelando cada vez más nítidamente la insuficiencia del frío racionalismo de su libro del 42 para 
conseguir este resultado. Hobbes vuelve entonces a utilizar, a partir de los 50, muchos de los recursos retóricos y estilísticos que había aprendido en la escuela de la gran tradición humanista en que se había formado, y entre ellos, por supuesto, el recurso del humor (de un humor mordaz y despectivo: del tipo de humor satírico propio de las grandes tradiciones críticas del Renacimiento), al que Skinner da gran importancia.

Lo cierto es que Hobbes, que "vuelve", como digo, al lecho de esta tradición humanista clásica a partir de su gran libro del 51, había atravesado ya en su evolución intelectual, antes de que se operara en él la decisiva transformación que lo llevaría a su racionalismo militante de los 40 y a sus conocidas críticas a los retóricos y los predicadores, un período de "humanismo temprano", como lo llama Skinner, que acaso convendría examinar mejor. A ese período (a ese primer período humanista, entonces, al que seguirían después el período racionalista del De Cive y el período neohumanista del Leviatán) corresponden, como se sabe, sus traducciones de la Retórica de Aristóteles y, por supuesto, de La guerra del Peloponeso de Tucídides, que ya citamos. Pero no sólo eso. Casi al pasar, en el curso del capítulo de Reason and Rhetoric... dedicado al humanismo juvenil de Hobbes, Skinner menciona una colección de escritos atribuidos al patrón del filósofo, Lord Cavendish, y publicada anónimamente en 1620 bajo el título de Horae Subsecivae, "Tiempo de ocio", e indica que la primera parte de este libro consiste en una versión apenas ampliada de un conjunto de ensayos breves ya dados a conocer antes por Cavendish, y que la segunda parte está integrada por cuatro discursos, entre los que destaca especialmente el tercero, "Against Flatterie", "Contra la adulación”, originalmente publicado por Cavendish en 1611.

De los otros tres discursos, Skinner sólo menciona, en una nota a pie de página, los nombres: "Upon the begining of Tacitus", "Of Rome" y "Of Lawes", observa que "Sin duda Cavendish y Hobbes discutieron sus contenidos" y sin mayores detalles agrega la primera indicación que yo tuve (cierto que, en su momento, cuando leí el libro de Skinner, no le presté la más mínima atención) sobre la autoría de estos trabajos: "Parece ser", dice, "que Hobbes puede haber escrito en realidad algunos de estos discursos", tras lo que nos invita, en otra nota al pie, a echar un vistazo al "análisis computacional" reportado en un artículo de Noel Reynolds y John Hilton en un número de 1993 de History of Political Thought. ¿En 
qué consiste ese "análisis computacional"? En la aplicación a los tres únicos discursos del Horae de autoría incierta de un "método científico" (cuyos detalles se me escapan) que, según sus practicantes, demostraría de manera inefable la presencia de la mano de Hobbes detrás de ellos. Esta autoría de Hobbes es dada ya por segura en la edición de los Tres discursos -como fueron titulados- realizada en 1995 por el propio Reynolds y por Arlene Saxonhouse (Saxonhouse había sostenido ya su hipótesis de que Hobbes era el autor de los tres duscursos en su tesis doctoral de 1972, que orientó el trabajo posterior de Reynolds y Hilton), y en 1999 Aloysius Martinich considera ya esta atribución la opinión aceptada entre los expertos.

Y no hay duda de que se trata de la opinión correcta. Más allá de las seguras bondades del método aplicado a los Discursos por Reynolds y Hilton (que soy por supuesto incapaz de justipreciar), son los propios contenidos de los tres textos los que no sólo nos convencen de que sólo Hobbes pudo ser su autor, sino que además nos permiten conocer algunas de las fuentes de ideas que el filósofo desplegó más tarde en sus libros más famosos, y especular sobre las continuidades y rupturas entre el pensamiento de su juventud y el de su madurez intelectual. A esa tarea, que no me propongo realizar acá, pueden contribuir decisivamente el erudito trabajo de comparaciones, cotejos y remisiones realizados, para la traducción, el estudio preliminar y las notas a una reciente edición argentina de los tres Discursos hobbesianos (la primera, por cierto, que existe en español, y me deberán ustedes disculpar que mi exposición adquiera en este punto un carácter obscenamente publicitario), por Andrés Jiménez Colodrero y por Andrés di Leo.

No voy a extenderme, como digo, sobre esta cuestión, que sin duda ameritaría estudios específicos que quizás -seguramente- se estén desarrollando ya por todas partes. Por un lado, es interesante destacar la coherencia entre el análisis que en el más sustancioso de los tres Discursos realiza el joven Hobbes sobre los capítulos iniciales de los Anales de Tácito y el conjunto de la obra posterior de nuestro filósofo, especialmente a la luz de las interesantes observaciones que realizó Andrés Rosler, en este mismo coloquio, sobre la pertenencia de Hobbes a la gran tradición tacitista moderna: habría mucho para decir sobre este punto, pero aquí no puedo hacer más que dejar planteada la cuestión. Por otro lado, no es 
menos interesante verificar la incoherencia, por así decir, entre la idea de "ley" que se desprende del breve discurso "Sobre las leyes" y la teoría sobre las leyes que puede encontrarse en la obra más conocida del filósofo de Malmesbury. Sobre todo si, en lugar de derivar de esta ostensible discordancia alguna apresurada sospecha sobre la autoría hobbesiana de este discurso (sin duda confuso y como preparatorio de desarrollos que apenas empezaban a insinuarse), hacemos el ejercicio de adentrarnos, justamente, en el interior de sus inconsistencias y tensiones, para verificar allí la manera tortuosa en la que, como entre las grietas de una idea todavía clásica sobre el orden natural de las cosas, se va abriendo camino, en el pensamiento de Hobbes, la sospecha de que las cosas no están "naturalmente" ordenadas, y de que ordenarlas es exactamente la tarea de las leyes humanas. Por cierto, sería interesante buscar en ese texto de juventud de Hobbes por el menos la prehistoria de algunas de las tensiones que fueron discutidas en este coloquio alrededor del problema de la ley natural y la ley civil.

Dejo para el final el magnífico discurso sobre Roma. Escrito por Hobbes a la vuelta de un viaje costeado por su patrón, el viejo Cavendish, este texto se caracteriza por un estilo lacónico y templado: es la concisa crónica de alguien que tiene que rendir cuentas y mostrar que no ha dilapidado el dinero; es - por lo demás- el texto de un joven preceptor de quien no se esperan grandes opiniones personales ni juicios especialmente categóricos sobre las materias acerca de las que habla. Así, hay una prudencia llamativa y una suerte de tono de "informe" en todo el texto. Sin embargo, es imposible no advertir la ironía apenas contenida, el sarcasmo apenas disimulado detrás de esta voz parca y descriptiva, la carcajada que pugna por abrirse paso entre las líneas de este texto de un lacayo austero. Valdría la pena considerar, por ejemplo, todo lo que dice Hobbes sobre "las estrategias que usan los católicos para la confirmación y el establecimiento de su religión" (que son cuatro, dice: las demostraciones externas de devoción, los actos de caridad, la ostentación de milagros y la instrucción), sobre las rentas del Papa y el orgullo de los cardenales: el proverbial anticatolicismo de Hobbes está ahí todo entero, y sin menos brillo y gracia que el que lo vestiría en sus textos de madurez. Podría destacarse también, de manera más particular, la atención especial que presta Hobbes a las actividades de los jesuitas, que anticipa el interés 
con que tratará a los miembros de esa orden en la historia de la guerra civil inglesa que trazará varias décadas después en el Behemoth.

Pero prefiero detenerme en un solo punto, muy breve. Escribiendo sobre el Panteón, Hobbes apunta escuetamente, casi como un guía de turismo haciendo su trabajo informativo, que "antiguamente era un templo dedicado a todos los dioses; ahora se lo ha convertido para honrar a todos los santos". La frase llama la atención por dos razones. Primero, porque anticipa casi a los gritos las humoradas que tres décadas más tarde se permitirá Hobbes, sobre exactamente la misma cuestión, en la parte final del Leviatán, cuando comenta (en lo que por lo demás constituye una sagaz observación sobre los límites del monoteísmo cristiano) que las iglesias cristianas se apropiaron de las viejas estatuas paganas de los dioses del Olimpo y apenas debieron hacerle unos pocos retoques de superficie para reciclarlas como lozanas representaciones de los santos del Cielo. Después, porque en estas consideraciones Hobbes repite respecto a los monumentos y a las estatuas lo que ya le oímos decir respecto a las palabras: que son significantes vacíos, insignias desamarradas de cualquier relación necesaria con el mundo, y que por lo tanto pueden ser llenadas por múltiples y distintos significados particulares. "Palabras, palabras, palabras..." -le habíamos oído decir al príncipe Hamlet- : palabras y no cosas, palabras vacías de significado, a las que las luchas de los hombres van cargando con éste o con aquél, y a las que sólo la soberanía de un Estado puede dar en un momento dado un único significado verdadero. "Estatuas, estatuas, estatuas..." -parece decirnos ahora Hobbes- : estatuas y no dioses ni santos ni nada, estatuas a las que un poco de pintura puede convertir en representación de otra deidad, a las que la historia de las religiones fueron cargando sucesivamente con valencias diferentes y a las que sólo la soberanía de un Estado puede dar en un momento dado un significado universal y obligatorio.

He tratado de argumentar que en esta comprensión hobbesiana de las cosas radica la razón del modo trágico en el que Hobbes piensa la historia, y también del modo cómico en el que la narra. En el Discurso sobre Roma, sin ir más lejos (y ya para terminar), Hobbes observa que alguno de los enormes y fastuosos baños de los antiguos romanos, construidos durante años por medio del trabajo forzado de multitudes de cristianos, está hoy convertido en una Iglesia y un convento. ¿Cómo no sonreír 
frente a esa graciosa (pero en el fondo aciaga) constatación del absurdo de las cosas, de lo inconstante de las fuerzas de los hombres en la historia? Durante toda su vida y a lo largo de toda su obra Hobbes pensó sobre este absurdo, esta inconstancia, esta fragilidad. Esta tragedia. Aquí he querido mostrar que en ocasiones lo hace de manera muy graciosa, muy cómica, y, justo gracias a esa comicidad, muy efectiva, como habían sabido hacerlo antes que él los grandes dramaturgos del Renacimiento, de los que tal vez esté menos alejado de o que la ausencia de referencias a ellos en sus obras nos ha habituado a suponer.

\section{Referencias bibliográficas}

FOUCAULT, M. 1966. Les mots et les choses. París: Gallimard.

FREUD, S. 1982. “'Por qué la guerra? (Einstein y Freud)”. En OC, vol. XXII. Buenos Aires: Amorrortu.

HOBBES, T. 1993. El ciudadano. Madrid: CSIC/Debate.

---. 2006. Discursos histórico-políticos. Buenos Aires: Gorla.

---. 1959. Leviathan. Londres: Dent \& Sons.

MACPHERSON, C. 1962. A teoria política do individualismo possessivo:

De Hobbes a Locke. Río de Janeiro: Paz e Terra.

MAQUIAVELO, N. 1996. Discursos sobre la primera década de Tito Livio. Madrid: Alianza.

---. 1990. El príncipe. Buenos Aires: Marymar.

RIBEIRO, R. J. 1984. Ao leitor sem medo: Hobbes escrevendo contra o seu tempo. São Paulo: Brasiliense.

SHAKESPEARE, W. 1985. Hamlet. Cambridge: CUP.

SIPERMAN, A. 2000. Una apuesta por la libertad: Isaiah Berlin y el pensamiento trágico. Buenos Aires: De la Flor.

SKINNER, Q. 1978. Foundations of modern political thought. Cambridge: CUP. 
SOARES, L. E. 1995. A invenção do sujeito universal: Hobbes e a política como experiência dramática do sentido. Campinas: Editora da Unicamp.

STRAUSS, L. 1963. The political philosophy of Hobbes. Chicago:

University of Chicago Press.

WOLIN, S. 1973. Política y perspectiva: Continuidad y cambio en el pensamiento político occidental. Buenos Aires: Amorrortu.

doispontos, Curitiba, São Carlos, vol. 6, n. 3 - especial, p.65-83, abril, 2009 